\title{
"Do Health Insurance Scheme" Affect the Livelihood of People in the Rural Area of Ghana: Emperical Evidence from Adaklu Anyigbe
}

\author{
Phanuel Mawuli Kofi Segbefia \\ School of Management, Jiangsu University, 301 Xuefu Rd, Jingkou, Zhenjiang, Jiangsu Province, China \\ Yinghua Chen \\ School of Management, Jiangsu University, 301 Xuefu Rd, Jingkou, Zhenjiang, Jiangsu Province, China \\ Emmanuel Kwaku Manu \\ School of Management, Jiangsu University, 301 Xuefu Rd, Jingkou, Zhenjiang, Jiangsu Province, China
}

\begin{abstract}
The main objective of establishing the National Health Insurance Scheme (NHIS) is to protect the poor and put health in the hands of the people. It also aim to provide health services for all by abolishing the "cash and carry" system in which patients are asked to pay before they are treated. This study was conducted to assess a new method of financing Health Care in Ghana, evaluation of Mutual Health Insurance Scheme in Adaklu Anyigbe. A questionnaire was designed using structured questions to collect primary data from health facilities and clients of the NHIS. Personal interviews were held to solicit views and comments from some respondents. The results show that the availability of adequate funds for health care services is very important for the survival of the health insurance scheme. Adequate funding for health care services will assist in meeting health care services and delivery requirements for health service facilities and clients in Ghana. Meeting Ghana's health requirements will require the adoption of effective policies and guiding principles that integrate the input and concerns of all stakeholders from the health care business.
\end{abstract}

Keywords; Health insurance scheme; Health care delivery; rural people; Adaklu Anyigbe

DOI: $10.7176 / \mathrm{EJBM} / 11-26-11$

Publication date:September $30^{\text {th }} 2019$

\section{INTRODUCTION}

The UN Millennium Development Goals 3, 4 and 5 are specifically about reducing child mortality, improving maternal health and combating the spread of HIV / AIDS respectively (Merson, 2006)(UN, 2006). But over the years some progress has been made in the health sector but this is still below measure. While temporary funding for some pilots in the future might be obtained through international donors, ultimately resources to fund district health insurance schemes must be provided through social health insurance contributions or general tax revenues. One of the main problems of NHIS is ensuring efficiency and sustainability. After the introduction of the "cash and carry" system to the Ghana health sector in the late 1980s, many patients began to have difficulty paying their health care costs. As a result, many do not go to the hospital until it's too late or their illness has advanced to a more complicated phase. Others who were cared for and cared for then escaped without paying their care. Many people cannot afford to pay for their care.

Following the introduction of the national health insurance scheme, the National Health Insurance Authority was formed under the 2003 National Health Insurance Act, Law 650, as a corporate legal entity, with lasting succession, the Official Seal, which can sue and be sued on its own. Under the law, there is a National Health Insurance Authority that licenses, monitors, and regulates the operation of health insurance schemes in Ghana including the District Mutual Health Insurance Scheme (DMHIS), Private Mutual Health Insurance Scheme (PMHIS), and Private Commercial Health Insurance Scheme (PMHIS).

According to (McPake, Kutzin, \& Organization, 1997) funding for health care financing under the National Health Insurance Scheme as stipulated by Law 650, comes from Funds created by the Act, with revenues from two main sources, also created by the law. These are the National Health Insurance Retribution (NHIL), 2.5 percent percentage of the Value Added Tax (VAT), and the 2.5 percent transfer of the existing Social Security and National Insurance Guarantee (SSNIT). Another financial source for the Scheme is the National Health Insurance Fund which has been established by the Government to help bridge the gap between the premiums of contributors and the scheme and funding for the poor, who cannot pay their premiums. The government has decided to access funds from the National Social Security and Trust Insurance (SSNIT) to form a Scheme. One of the main problems affecting NHIS is to ensure financial sustainability, which refers to long-term stability and income generating potential. Financial sustainability is also a big challenge for Adaklu Anyigbe Municipal Mutual Health.

To provide an appropriate source of funding for health insurance, whether national or special scenarios, 
relevant to the success of the insurance projects. In Ghana the issue of health care funding is very important in discussions about providing appropriate and affordable funds for health care services in Ghana. Health care services in Ghana are sourced from different agencies and partners. Apart from the premiums paid by members, the reciprocal district health insurance scheme receives regular funding from the central government. The central government funding is taken from the national health insurance fund. Each Ghanaian worker pays two and half percent of their social security contribution to this fund and the VAT rate in Ghana also has a two-and-a-half percent component that goes into the fund (Dixon, Tenkorang, \& Luginaah, 2013).

The universal health care system varies according to the level of government involvement in providing health care or insurance. In some countries, such as Britain, Spain, Italy and the Nordic countries, governments have a high level of involvement in the commissioning or delivery of health care services and access is based on housing rights rather than on insurance purchases. Others have a far more pluralistic delivery system that is based on compulsory health with a level of contribution insurance related to salary or income, and is usually funded by employers and beneficiaries jointly (Wikipedia, 2011). Sometimes health funds come from a mixture of insurance premiums, mandatory contributions related to salaries by employees and / or employers for regulated sick funds, and by government taxes. This insurance-based system tends to reimburse private or public medical provider fees, often at tightly regulated rates, through publicly owned or publicly owned health insurance. Some countries such as the Netherlands and Switzerland operate through privately owned but highly regulated private insurance which is not permitted to benefit from the compulsory insurance element but can profit by selling additional insurance. (Wikipedia, 2011).

Although OECD members funded through social insurance have a higher average total expenditure on health, tax funding can be as inefficiently used as other types of funding. The Netherlands and Germany illustrate that cost control can be effective in the insurance system (Mossialos \& Le Grand, 1999). When considering technical efficiency, it is the system and incentives in which providers, payers and patients operate that are important. (Mossialos, Dixon, Figueras, \& Kutzin, 2002), hypothesize that higher spending can be caused by greater transparency, less political interference, greater relationship between contributions and benefits, and the existence of a single or multiple insurance companies in the social insurance system. Therefore the greater role of various health stakeholders is very important to secure funding opportunities that are suitable for health services and insurance.

Most country systems display a mix of the five models. One study based on data from the OECD concluded that all types of health care financing are "compatible with" efficient health care systems. This study also found no relationship between financing and cost control (Glied \& Lleras-Muney, 2008). The term health insurance is generally used to describe a form of insurance that pays medical expenses. Sometimes it is used more broadly to include insurance that includes disability or long-term care or custodial care needs. This can be provided through social insurance programs, or from private insurance companies. This can be obtained as a group (e.g.by the company to protect its employees) or purchased by individual consumers. In each case, premiums or taxes protect the insured from high or unexpected health care costs. The case is similar for Ghana, which also has different health care financing arrangements in its operations because some health care providers accept cash and carry health insurance policies. By estimating the overall costs of health care costs, routine financial structures (such as monthly premiums or annual taxes) can be developed, ensuring that money is available to pay for health care benefits specified in the insurance agreement. Benefits are usually managed by government agencies, non-profit health funds or companies operating for profit.

In the Ghanaian perspective, for example, health insurance recipients pay an annual premium to access health services through NHIS every year (Wells \& Claxton, 2008). Many forms of commercial health insurance control their costs by limiting benefits paid through deductibles, co-payments, coinsurance, policy exclusions, and total coverage limits and will greatly limit or refuse coverage of pre-existing conditions. Many government schemes also have joint payment schemes, but exceptions rarely occur due to political pressure. Larger insurance schemes can also negotiate fees with providers. (Kerrigan et al., 2002) stated that, according to the Health Research Agency and the Quality, Literacy and Health Results Report January 2004, low health literacy is associated with higher rates of hospitalization and higher use of emergency services. This evidence-based literature review highlights many studies that provide detailed analyzes of the correlation between low health literacy and poor health. This shows the positive influence of education on knowledge about health services and childbirth services.

Many forms of social insurance schemes control their costs by using the bargaining power of the people they represent to control costs in the health service delivery system. For example, by negotiating drug prices directly with pharmaceutical companies, or negotiating standard costs with the medical profession. Social schemes sometimes feature income-related contributions as part of a scheme to provide universal health care, which may or may not involve the use of commercial and non-commercial insurance. Basically, rich people pay proportionately more into schemes to meet the needs of relatively poor people who therefore contribute proportionately less (Morris et al., 1995). There is usually a limit on the contribution of rich and minimum payments that must be made by the insured (often in the form of minimum contributions, similar to deductibles in 
the commercial insurance model). Premium payments are not discriminatory for the rich and poor because they all pay equally. However, the cost of accessing health services can increase with the quality of health services that they want to access because clients may have to pay more if they need excellent health care services to provide. In addition to these traditional health care financing methods, some lower income countries and development partners are also implementing non-traditional or innovative financing mechanisms for scaling up delivery and sustainability of health care, such as micro-contributions, public-private partnerships, and market-based financial transaction taxes. For example, as of June 2011, UNITAID had collected more than one billion dollars from 29 member countries, including several from Africa, through an air ticket solidarity levy to expand access to care and treatment for HIV/AIDS, tuberculosis and malaria in 94 countries (Organization \& Unicef, 2011).

\subsection{Clients Concerns about Satisfaction with Health Care Financing in Ghana}

Health service financing has received several comments, especially in terms of financing and service delivery in many countries including Ghana. In a study at Alma Ata, India it was found that the increased emphasis on client satisfaction was driven by the perceived need for democratization of primary health care. Patient satisfaction as a measure of health care is an important outcome measure. This is useful in assessing consultation and communication patterns. If used systematically, feedback allows choices between alternatives in organizing or providing health care (Lambert, 1978). The efficacy of medical care is enhanced by greater patient satisfaction. This can also be taken as a proxy measure for the quality of health care. Their study is limited to the views of health service users and identifies various obstacles in the delivery of health care services that may be important for health service users but may seem trivial to health workers. Combining user views in health service management will result in fewer dissatisfied users (Ortola et al., 1993). It is therefore important to note that combining the views of clients and facility management in the overall NHIS work plan and Adaklu Anyigbe Joint Health Insurance Scheme is very important for a successful health insurance plan in Ghana.

In addition the slow pace in recruiting new and contract staff into the Health Service which is attributed to delay in the issuance of Financial Clearance by Ministry of Finance and Economic Planning. There is ample evidence of large numbers of doctors, nurses, pharmacists, laboratory technicians/technologists, administrators, etc who have worked for more than one year without salaries. It is the candid opinion of the Association that if this problem is not urgently resolved, the quest by the government to attract and retain Ghanaian health professionals cannot be realized and the brain drain in the health sector will continue (Agamah, 2011).

A study by (Patro et al., 2008) shows that the average waiting time for accessing health is similar in community surveys and in exit interviews, which is around 30 minutes. Waiting time correlates well with average waiting time in the same setting. It also emerged as one of the main areas of dissatisfaction with health services as well as causes of non-utilization. A reduction in waiting time can increase patient satisfaction and increase the utilization of health services provided by mobile health clinics. The average consultation time in a community survey is more than 5 minutes while it is reported to be less than 5 minutes in exit interviews (Patro et al., 2008). However, this is twice as high as reported from other studies in the same setting. This could be an explanation for a higher level of satisfaction with domains related to doctors vs. physician / health staff behavior, doctor competence, provision of information, and physical examination. The unavailability of certain drugs and investigations emerged as the main areas of client dissatisfaction. This correlates with other research findings. This is due to the general perception that as a government organization, mobile health clinics must provide all medicines and investigations free of charge. However this can challenge NHIS in Ghana because this scheme can make cash because they currently face many challenges in terms of meeting their operational costs.

The United States system of using health insurance as a means of financing health care costs has been criticized by (Berwick, Nolan, \& Whittington, 2008). They state that private plans are attractive because of their ability to be responsive to consumer demand for their choices and innovations resulting from profit motives and the desire to attract a larger registration base, "they also have weaknesses. Industry consolidation" has not led to strong insurance companies who are willing or able to negotiate effectively with the dominant hospital system, "and the insurance market has been dominated by a small number of large insurance companies" with "shadow pricing" by smaller insurance companies. However this may not be persistent in Ghana because they are a standard national scheme that provides health service delivery services to the population.

Insurance companies have high administrative costs because many witness with NHIS (Pleis \& Lucas, 2009). In the United States, for example, private health insurance is an important part of the US economy which directly employs (in 2004) nearly 470,000 people with an average salary of \$ 61,409 . Health insurance companies actually do not provide traditional insurance, which involves collecting risk, because most buyers actually face the danger they "insure" against. On the contrary, as Edward Beiser and Jacob Appel put it separately, health insurance is better regarded as a low-risk money manager who pockets interest on what is actually long-term savings (Das et al., 2008).

According to a study by the pro-health reform group published February 11, the five largest health insurance companies in the country posted a 56 percent profit in 2009 compared to 2008 . The insurance (Stone, 2010) covers 
most Americans with Health Insurance. The Association of Health Services Administrators-Ghana (Dixon et al., 2013 ) issued a statement in connection with their concerns about NHIS in Ghana. It was revealed that the continued implementation of the liberation policy for the poor, under five years, and free shipping served as a disincentive for people to register into the scheme. Moreover, inadequate politicization and public sensitivity to the scheme is a major obstacle in meeting the scheme's goal of providing quality and affordable health care for the people of Ghana. Financial difficulties were also expressed and this was related to an undue delay in the release of funds from the National Health Insurance Board (NHIC) to the district-level joint health scheme to support payment of claims made under the scheme.

\subsection{Challenges Facing the National Health Insurance Scheme in Ghana}

The recent controversies surrounding the one-time premium payment under the National Health Insurance Scheme points to the obvious: that the healthcare needs of Ghanaians cannot be mortgaged. Access to healthcare is a necessity and clearly so, Ghanaians should have affordable healthcare as and when the need arises. This was the guiding philosophy that called for the National Health Insurance. Although the introduction of the NHIS has brought an inescapable relief to the poor, majority of Ghanaians in the rural areas and urban slums still cannot access health care. However, the few that can seek health care outside are always responsible for toying with our health system. This ought to be jettisoned. There are myriad of challenges facing the health sector, and particularly, the National Health Insurance Scheme (NHIS). These challenges includes inter alia: lack of health facilities in many communities in the country, inadequate personnel in many of the facilities, and logistics for health care delivery (Gumah, 2010). In Ghana the NHIS has not fared differently as it continues to grapple with the challenges of funds, adequate and well trained staff including others.

According to (Agamah, 2011) NHIS writing in Ghana reiterates the concerns of the CEO, NHIS, Ghana that, the CEO has observed that there will soon be legislation to allow the scheme to operate as an independent legal entity with due regard for accountability and efficiency. Speaking to delegates from Congo Brazzaville, the CEO acknowledged that the scheme had gone through several challenges. We don't have a perfect system but what's good is that we have a good political system, "he said. He explained that this system faces the challenge of spending because the outflow exceeds inflows, adding that claim payments cover more than 75 percent of the total revenue generated from taxes and Social Security and National Insurance Guarantees (SSNIT) He added that GH $\notin 394.27$ million representing 76.2 percent was used as payment of claims for 2010 , and this is a major channel on NHIS financial viability.

(Kambris, Cook, Phuc, \& Sinkins, 2009) also added voice to the challenges faced with the smooth administration of health service provision by NHIS in Ghana. The Health Insurance Scheme (NHIS) has the potential to cripple the provision of health services in the country. "The challenge in managing NHIS is not from the doctors and in this case the providers. If current reforms are not accelerated, NHIS will certainly not be sustainable," he said. He further added that NHIS was one of the best things that happened to the health care delivery system in the country. However, problems in managing the scheme especially the long delay in reimbursement affects the ability of the institution to provide services to the community. "I have reliable information that some private providers have opted out of the Scheme or refused to continue providing services," he said. More than that he asks the National Health Insurance Authority to regularly review rates while ensuring reimbursement of claims submitted by providers to avoid compromising quality care to clients.

\subsection{DATA AND METHODOLOGY}

\subsection{Area of Study}

This study was conducted in a Life Insurance Company in Adaklu Anyigbe to have a deep understanding and appreciation of how customers assess the industry performance. It also aim to identify innovative measures and technology delivery channels that have been used by life insurance companies to ensure comfortable insurance. This research is limited to the Life Insurance Company at Adaklu Anyigbe.

\subsection{Population}

The population is for the Municipality of Adaklu Anyigbe, which is 147,301 people (Adaklu Anyigbe, 2019). Researchers have worked at Adaklu Anyigbe for several years and believe that it is appropriate to investigate these variables so that they can be replicated in other fields. The focus is on staff and clients in the National Health Insurance Scheme including healthcare providers. These include hospitals, clinics, maternity hospitals, medical centers and pharmacy shops that partner with the Adaklu Anyigbe Mutual Health Insurance Scheme in providing health care for people.

\subsection{Sampling Design, Size and Procedure}

Descriptive analytic sample survey is the research design used for this study. (Fourer, Gay, \& Kernighan, 1987) sees descriptive surveys as a process of collecting data to test hypotheses or answer questions about the status of 
research. Therefore the researcher chose to design a descriptive survey because it considers the research objectives; it is the right design that can lead to meaningful description images of research.

The sample size of two hundred and thirteen respondents consisted of clients who had registered with the scheme, the facilities and the scheme itself was used for the research. The distribution consisted of one hundred twenty (120) NHIS clients, eighty NHIS health service providers (80) and thirteen (13) scheme staff.

\section{Results and Discussion}

\subsection{General Characteristics of the Respondents}

The survey showed that $23.5 \%$ (50) were men compared to $75.6 \%$ (161) women. Of the 23.55 men, 9.0\% (19) came from the staff category, $12.8 \%$ (27) for facility clients and 1.9\% (4) staff from the Adaklu Anyigbe Health Insurance Scheme.

\section{Table 1 Sex against Category of Respondents}

\begin{tabular}{|c|c|c|c|c|}
\hline & \multicolumn{3}{|c|}{ Category of respondent } & Total \\
\hline Sex of male & Staff facility & Client facility 27 & Staff of NHIS & 50 \\
respondent & 19 & $12.8 \%$ & 4 & $1.9 \%$ \\
& $9.0 \%$ & & 8 & 161 \\
& 56 & 97 & $3.8 \%$ & $76.3 \%$ \\
\hline Female & $26.5 \%$ & $46.0 \%$ & 12 & 211 \\
& 75 & 124 & $5.7 \%$ & $100.0 \%$ \\
\hline
\end{tabular}

For $76.3 \%$ of women, $26.5 \%$ (56) came from facility category staff, $46 \%$ for facility clients and $3.8 \%$ of NHIS staff. Summary data for Table 1, shows that women represent a higher percentage of respondents including the fact that women dominate the level of representation for various categories.

\subsection{Clients' Perception and Satisfaction with Financing Health Care from the National Health Insurance Scheme (NHIS) in Ghana}

\subsubsection{Aspects and Levels of Satisfaction with the Service of the NHIS}

The researcher is also interested in knowing which aspects of providing NHIS services are satisfactory for respondents. Therefore the survey shows that $17.1 \%$ (36) are satisfied with claim payments, $20.4 \%$ (43) for customer service shipments, $45.5 \%$ (96) quick responses to complaints and $17.1 \%(36)$ of these rather focused on other choices of service delivery other than those chosen by other respondents.

Table 2 Aspects and Levels of Satisfaction with the Service of the NHIS

\begin{tabular}{|c|c|c|c|c|}
\hline \multirow{2}{*}{\begin{tabular}{lccc} 
Aspect & of & \multicolumn{2}{c}{ insurance } \\
scheme that & you are \\
satisfied & & & \\
\end{tabular}} & \multicolumn{3}{|c|}{$\begin{array}{l}\text { Extend to which NHIS addresses the health concern of } \\
\text { Ghanaians }\end{array}$} & \multirow[t]{2}{*}{ Total } \\
\hline & Very satisfied & satisfied & Less satisfied & \\
\hline Payments of claims & $\begin{array}{c}0 \\
0 \%\end{array}$ & $\begin{array}{c}0 \\
0 \%\end{array}$ & $\begin{array}{c}36 \\
17.1 \%\end{array}$ & $\begin{array}{c}36 \\
17.1 \%\end{array}$ \\
\hline Customer service & $\begin{array}{c}5 \\
2.4 \%\end{array}$ & $\begin{array}{c}38 \\
18.0 \%\end{array}$ & $\begin{array}{c}0 \\
0 \%\end{array}$ & $\begin{array}{c}43 \\
20.4 \%\end{array}$ \\
\hline $\begin{array}{l}\text { Prompt response to } \\
\text { complaints }\end{array}$ & $\begin{array}{c}49 \\
23.2 \%\end{array}$ & $\begin{array}{c}47 \\
22.3 \% \\
\end{array}$ & $\begin{array}{c}0 \\
0 \%\end{array}$ & $\begin{array}{c}96 \\
45.5 \% \\
\end{array}$ \\
\hline Non-of options & $\begin{array}{c}0 \\
0 \% \\
\end{array}$ & $\begin{array}{c}36 \\
17.1 \% \\
\end{array}$ & $\begin{array}{c}0 \\
0 \% \\
\end{array}$ & $\begin{array}{c}36 \\
17.1 \% \\
\end{array}$ \\
\hline Total & $\begin{array}{c}54 \\
25.6 \% \\
\end{array}$ & $\begin{array}{c}121 \\
57.3 \% \\
\end{array}$ & $\begin{array}{c}36 \\
17.1 \%\end{array}$ & $\begin{array}{c}211 \\
100 \%\end{array}$ \\
\hline
\end{tabular}

Of the $82.9 \%$ (175) respondents who said NHIS handled the health problems of Ghanaian citizens, $20.4 \%$ (43) said they were satisfied with NHIS customer service, $45.5 \%$ (96) for a quick response to complaints and with $17,1 \%(36)$ ) say that for different reasons than the options provided. For respondents who thought NHIS did not address their health problems, they all said they were satisfied with the delivery of the claim payment service. In a similar case (Agamah, 2011) advocating the incorporation of user views in health service management because this would lead to fewer dissatisfied users.

\subsubsection{NHIS and Access to Best Drugs against Extent to Which Health Concerns are addressed}

The survey also provided a feedback on whether clients of NHIS receive the best drugs when served under the health insurance scheme. It came out that $73.46 \%$ (156) of respondents think that they received the best drugs from the NHIS as against $26.54 \%$ (56) who thought otherwise 


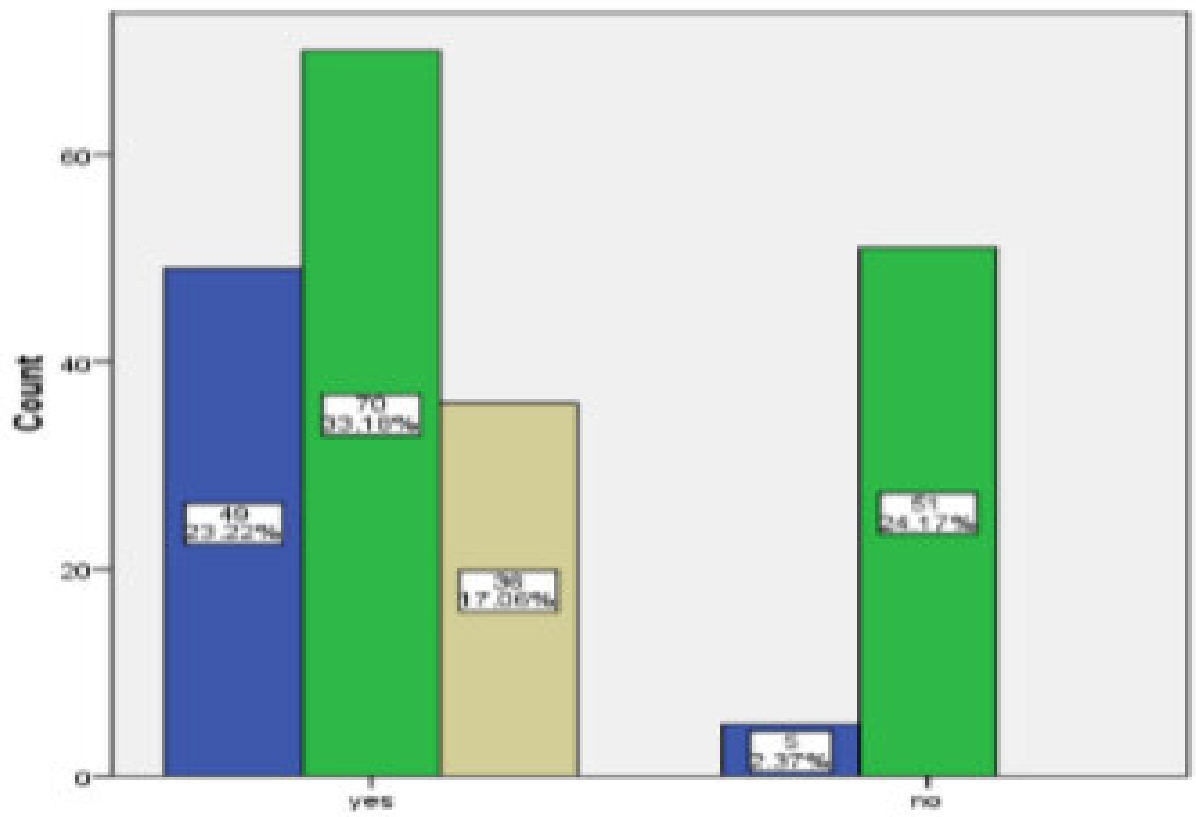

Extant to which Niris addresses the heait concern of Ghanaians Ditrenoly agree 口isoren

Figure 1: NHIS and Access to Best Drugs against Extent to Which Health Concerns are addressed

Of $73.46 \%$ (156) respondents think that they received the best medicine from NHIS, 56.40\% (119) said NHIS handled their health problems compared to $17.06 \%$ (36) who thought otherwise. However, all $26.54 \%(56)$ said that NHIS was meeting their health requirements. However, this study differs from (Agamah, 2011) which indicate that the main client dissatisfaction is the unavailability of certain drugs.

\subsection{Sustainability of the NHIS}

The survey showed that 59.24\% (125) of respondents agree that the NHIS is important in providing adequate funding for NHIS, 33.65\% (71) disagree where as 7.11\% (15) highly disagree. In all, the 211 respondents agree that there is room to look for possibilities of improving funding for NHIS services.(Emmerson, Frayne, \& Goodman, 2001) were rather of a different opinion to the process of deriving sustainable funding for NHIS. They rather stated that, in addition to the costs of fund collection, cost administration will be low with an efficient financing mechanism, leaving as much revenue as possible for actual health service provision.
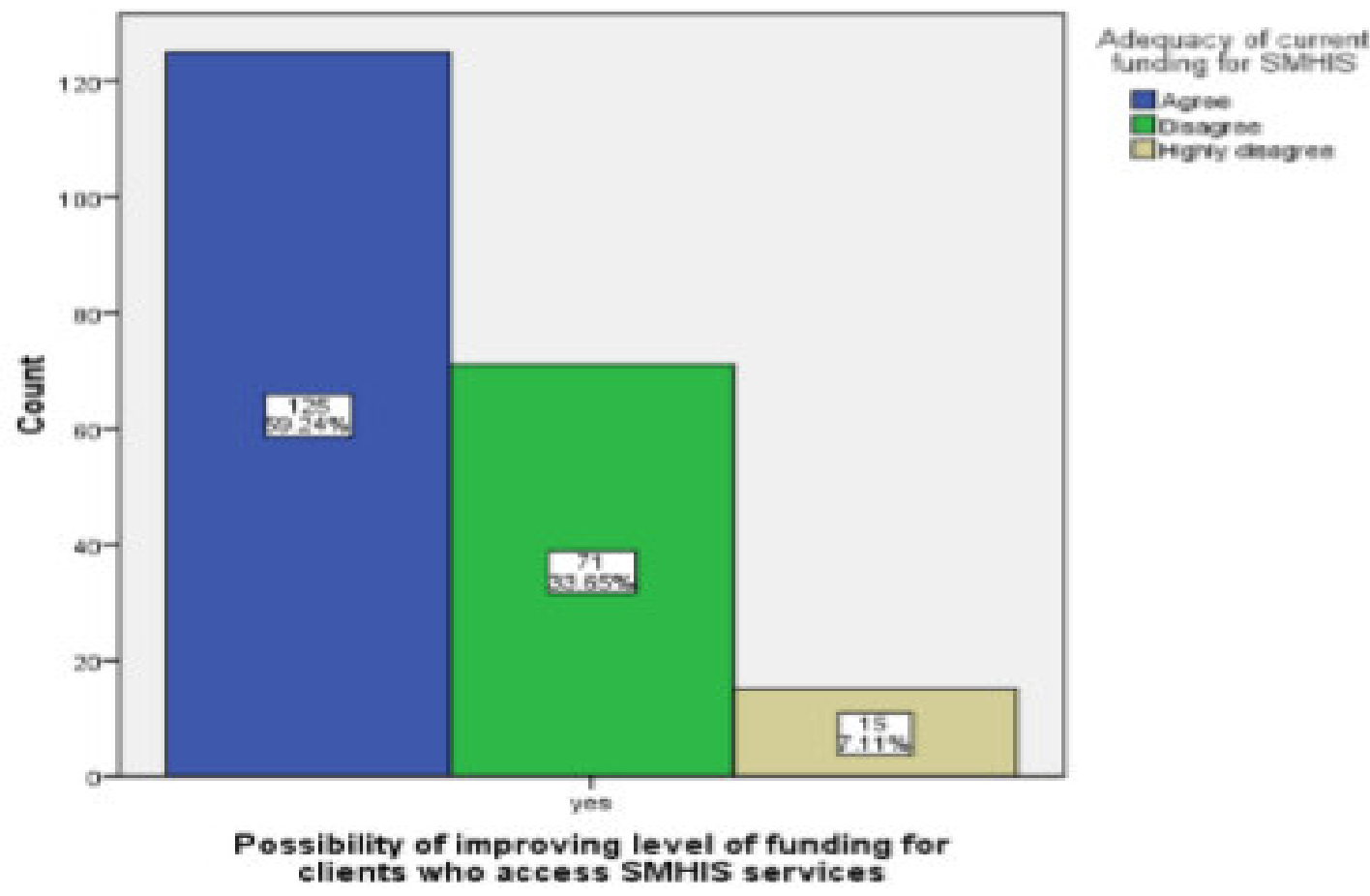

Figure 2 Suitable Funding against Adequacy of Current Funding Provided by NHIS 
(Gross, Mead, Ford, \& Klag, 2000) also rooted their support in reviewing the role of external support for the health system and showed that the sustainability of the system is the capacity of the health system to function effectively from time to time with a minimum of external input. Fond added that sustainability in funding must include securing adequate resources to enable increased effectiveness of health care, effective and efficient use of resources to meet health needs continuously and function with minimum external input. This is indeed an important tool for providing sustainable funding for the delivery of NHIS services.

\subsection{Whether NHIS is challenged in the Provision of Health Care Service to Facilities and Clients}

This research seeks information about whether NHIS is challenged in its work providing health care services for facilities and clients in the City of Adaklu Anyigbe. More than eleven percent of respondents agreed that NHIS was very challenged in its efforts to provide quality health care services for its facilities and clients. This response is contrary to $88.2 \%$ (186) of respondents who said they were challenged. The result is an indication that NHIS must re-examine its service delivery work and ensure that NHIS adequately improves the performance of its health services.

Table 3 Whether NHIS is challenged in the Provision of Health Care Service to Facilities and Clients

\begin{tabular}{|c|c|c|}
\hline & Frequency & Percentage \\
\hline Highly Challenged & 25 & 11.8 \\
\hline Challenged & 186 & 88.2 \\
\hline Total & 211 & 100.0 \\
\hline
\end{tabular}

Table 3 presents respondents' comments about the challenges faced in providing NHIS services. It turned out that $19.43 \%$ (41) respondents thought that the challenge was a shortage of staff in the NHIS office, $23.22 \%$ (49) a large client base, and this was the highest challenge identified by respondents.

\subsection{Addressing Challenges associated with Health Care Service delivery of NHIS}

In overcoming the challenges associated with providing services at NHIS, respondents advocated several important guidelines. This included 38.9\% (82) who requested improvements in staffing policies and NHIS practices. More than $6 \%$ (13) stated that staff training in the NHIS office should be the main effort chosen to improve service delivery

Table 4 Addressing Challenges associated with Health Care Service delivery of NHIS

\begin{tabular}{|c|c|c|}
\hline & Frequency & Percentage \\
\hline Improving staffing & 82 & 38.9 \\
\hline Inadequate trained staff & 13 & 6.2 \\
\hline Increasing funding & 63 & 29.9 \\
\hline Reducing institutional bureaucracy & 53 & 25.1 \\
\hline Total & 211 & 100 \\
\hline
\end{tabular}

Respondents who wanted the NHIS office reduce institutional bureaucracy were $25.1 \%$ (53) whilst $29.9 \%$ (63) said that funding should be improved at NHIS office. It was quite clear that respondents have greater inputs for improving service delivery at NHIS. In addressing the challenges of NHIS, the National Health Insurance Authority (NHIA), should set for itself, the arduous task of delivering on what it calls "the NHIS promise" (GajateGarrido \& Owusua, 2013). The salient ingredients of this gargantuan task set by the Authority for itself include a health insurance system that guarantees a one-time premium payment, a fully portable and sustainable national health insurance scheme fully supported and driven by a robust information technology (ICT) solution and an entirely restructured administrative and legal architecture of the Authority and scheme.

\subsection{Conclusion}

This study shows that several challenges affect the smooth operation and service delivery of the NHIS at Adaklu Anyigbe. Challenges identified include staff shortages, difficulties serving a large client base, inadequate funding, and corruption. Sources of funding for the operation and delivery of NHIS services are the National Health Insurance Authority (NHIA) and the National Insurance fund (NHIF) because the role of funding of the two bodies is very important for the life of the health insurance industry in Ghana. The majority of respondents indicated that funding provided by NHIA and NHIF was sufficient to support NHIS service operations.

A small number of respondents chose autonomy in generating funds for NHIS. Respondents unanimously agree that there are no other alternatives for the provision of quality and affordable health services in Ghana because they believe NHIS must be adequately supported to provide health service delivery functions. Customers' perceptions about the quality of healthcare delivery by NHIS vary. The majority of respondents were happy with the quick response to complaints while the minority was satisfied with the claim payment process. The majority of respondents agreed that NHIS provided the right medicine for them and that the delivery of NHIS health services was very good. Meeting Ghana's health requirements will require the adoption of effective policies and guiding 
principles that integrate the input and concerns of all stakeholders from the health care industry. Most concerning is the merging of perceptions of facility management and health care industry clients.

The availability of adequate funds for health care services is very important for the continuation of health insurance schemes and in this case meeting the requirements of health care services and delivery of health care facilities and clients in Ghana. Therefore, sustainable funding should be a guiding principle for exploring any options for providing funding for the delivery of appropriate health care services in Ghana. At present, NHIA and SMHIS are suitable for providing quality and affordable health services in Ghana, especially in the municipality of Sunyani. It is therefore important for the government, donor agencies and the Ghanaian community to actively embrace and support the activities and operations of these bodies in the provision of health care services to the common people of Ghana.

\subsection{Recommendation}

It is recommended that the NHIA should adopt ways to increase its funding challenges because the NHIA holds a key position to provide quality health care services for the Ghanaian people. NHIS must overcome this challenge by increasing staffing through effective and appropriate training programs, removing unnecessary obstacles that impede work progress.

The Ghanaian Government must review the NHIA 650 Law to fit the funding structure and NHIS requirements. It should also explore opportunities to increase the level of available funds for NHIS and related district offices. In this view too, management must actively pursue financial policies that seek to reduce waste and corruption and encourage good financial and management practices in all offices, facilities and client service points in the country.

The NHIS at Adaklu Anyigbe must often conduct action-oriented research; organize workshops and dissemination workshops to discuss best practices in the health insurance industry. It must also open customer service outlets in their offices and use such places to seek the concerns of partners and stakeholders in the health insurance industry.

\section{References}

Agamah, A. K. (2011). Financing Health Care in Ghana, an evaluation of the Mutual Health Insurance Scheme in Sunyani Municipality.

Berwick, D. M., Nolan, T. W., \& Whittington, J. (2008). The triple aim: care, health, and cost. Health affairs, 27(3), 759-769.

Das, R. R., Seshadri, S., Beiser, A. S., Kelly-Hayes, M., Au, R., Himali, J. J., . . . O'Donnell, C. J. (2008). Prevalence and correlates of silent cerebral infarcts in the Framingham offspring study. Stroke, 39(11), 29292935.

Dixon, J., Tenkorang, E. Y., \& Luginaah, I. (2013). Ghana's National Health Insurance Scheme: a national level investigation of members' perceptions of service provision. BMC International Health and Human Rights, $13(1), 35$.

Emmerson, C., Frayne, C., \& Goodman, A. (2001). Should private medical insurance be subsidised?

Fourer, R., Gay, D. M., \& Kernighan, B. W. (1987). AMPL: A mathematical programming language: AT \& T Bell Laboratories Murray Hill, NJ 07974.

Gajate-Garrido, G., \& Owusua, R. (2013). The national health insurance scheme in Ghana: Implementation challenges and proposed solutions.

Glied, S., \& Lleras-Muney, A. (2008). Technological innovation and inequality in health. Demography, 45(3), 741-761.

Gross, C. P., Mead, L. A., Ford, D. E., \& Klag, M. J. (2000). Physician, heal thyself?: regular source of care and use of preventive health services among physicians. Archives of Internal Medicine, 160(21), 3209-3214.

Gumah, T. A. (2010). EFFICIENCY AND EFFECTIVENESS OF CHPS ZONES IN PRIMARY HEALTH CARE DELIVERY IN THE NADOWLI DISTRICT, GHANA.

Kambris, Z., Cook, P. E., Phuc, H. K., \& Sinkins, S. P. (2009). Immune activation by life-shortening Wolbachia and reduced filarial competence in mosquitoes. Science, 326(5949), 134-136.

Kerrigan, D. C., Lelas, J. L., Goggins, J., Merriman, G. J., Kaplan, R. J., \& Felson, D. T. (2002). Effectiveness of a lateral-wedge insole on knee varus torque in patients with knee osteoarthritis. Archives of physical medicine and rehabilitation, 83(7), 889-893.

Lambert, P. (1978). A WHO collaborative study for the evaluation of eighteen methods for detecting immune complexes in serum. J. Clin. Lab. Immunol., 1, 1-15.

McPake, B., Kutzin, J., \& Organization, W. H. (1997). Methods for evaluating effects of health reforms: Geneva: World Health Organization.

Merson, M. H. (2006). The HIV-AIDS pandemic at 25-the global response. New England Journal of Medicine, 354(23), 2414-2417.

Morris, S., Kirstein, M., Valentine, M., Dittmer, K., Shapiro, D., Look, A., \& Saltman, D. (1995). Fusion of a 
kinase gene, ALK, to a nucleolar protein gene, NPM, in non-Hodgkin's lymphoma. Science (New York, NY), 267(5196), 316.

Mossialos, E., Dixon, A., Figueras, J., \& Kutzin, J. (2002). Funding health care: options for Europe: Open University Press Buckingham.

Mossialos, E., \& Le Grand, J. (1999). Cost containment in the EU: an overview.

Organization, W. H., \& Unicef. (2011). Global HIV/AIDS response: epidemic update and health sector progress towards universal access: progress report 2011.

Ortola, P., Blanquer, J., Rodríguez, J., Rodrigo, O., Villagrasa, F., \& Climent, J. (1993). User satisfaction in primary care: the results of a home survey. Atencion primaria, 12(9), 578-579, 581-572, 584-575 passim.

Patro, B. K., Kumar, R., Goswami, A., Nongkynrih, B., Pandav, C. S., \& Group, U. S. (2008). Community perception and client satisfaction about the primary health care services in an urban resettlement colony of New Delhi. Indian journal of community medicine: official publication of Indian Association of Preventive \& Social Medicine, 33(4), 250.

Pleis, J. R., \& Lucas, J. W. (2009). Summary health statistics for US adults; National Health Interview Survey, 2007: data from the National Health Interview Survey.

Stone, P. H. (2010). Health Insurers Funded Chamber Attack Ads. National Journal, 12.

Wells, G., \& Claxton, G. (2008). Learning for life in the 21st century: Sociocultural perspectives on the future of education: John Wiley \& Sons. 